\title{
Minireviews
}

\section{Perspectives on Wnt Signal Pathway in the Pathogenesis and Therapeutics of Chronic Obstructive Pulmonary Disease}

\author{
Jiao Qu, Li Yue, Jian Gao, and Hongwei Yao \\ The Second Affiliated Hospital, School of Pharmacy, Dalian Medical University, Dalian, Liaoning, China (J. Q., J. G.); The First \\ Affiliated Hospital, School of Pharmacy, Anhui Medical University, Hefei, Anhui, China (J.Q., J.G.); Department of Orthopedics, \\ Warren Alpert Medical School, Brown University/Rhode Island Hospital, Providence, Rhode Island (L.Y.); and Department of \\ Molecular Biology, Cell Biology and Biochemistry, Brown University Division of Biology and Medicine, Providence, Rhode \\ Island (H.Y.)
}

Received December 31, 2018; accepted April 4, 2019

\section{ABSTRACT}

Chronic obstructive pulmonary disease (COPD) is a chronic lung disease with progressive airflow limitation and functional decline. The pathogenic mechanisms for this disease include oxidative stress, inflammatory responses, disturbed protease/antiprotease equilibrium, apoptosis/proliferation imbalance, senescence, autophagy, metabolic reprogramming, and mitochondrial dysfunction. The Wnt signaling pathway is an evolutionarily conserved signaling pathway that is abnormal in COPD, including chronic bronchitis and pulmonary emphysema. Furthermore, Wnt signaling has been shown to modulate aforementioned cellular processes involved in COPD. From this perspective, we provide an updated understanding of the crosstalk between Wnt signal and these cellular processes, and highlight the crucial role of the Wnt signal during the development of COPD. We also discuss the potential for targeting the Wnt signal in future translational and pharmacological therapeutics aimed at prevention and treatment of this disease.

\section{Introduction}

Chronic obstructive pulmonary disease (COPD), a preventable and treatable disease of respiratory system, is characterized by irreversible airflow obstruction and loss of functional pulmonary tissue (Cabrera López et al., 2018). The main risk factor for COPD is the exposure to tobacco smoking. Other types of inhalations also contribute to the risk of developing COPD, such as toxic particles and gases in biofuels and air pollution. COPD will become the third ranked cause of death by 2020 (Cabrera López et al., 2018). Currently, effective treatments are limited to halting or reversing the progression of this disease. Therefore, understanding the molecular mechanisms underlying lung injury and repair processes would provide potential targets and strategies for intervening in the progression of COPD.

This work was supported by the Institutional Development Award (IDeA) from the National Institutes of Health National Institute of General Medical Sciences (Grant P20GM103652, to H.Y.), and the Chinese National Natural Science Foundation Project (No. 81274172, 81473267, to J.G.). The authors declare that they have no conflicts of interest with the contents of this article. https://doi.org/10.1124/jpet.118.256222.
Accumulating evidence shows that the Wnt signal pathway is abnormal during the development of COPD (Wang et al., 2011; Heijink et al., 2013; Baarsma et al., 2017; Skronska-Wasek et al., 2017). In general, the Wnt canonical pathway is downregulated, whereas noncanonical signaling is upregulated in COPD. In this review, we discuss the role of the Wnt signal in the pathogenesis of COPD and potential therapeutics for this disease that target the Wnt signal pathway.

\section{Cellular Processes in the Pathogenesis of COPD}

It is well known that oxidative stress, inflammatory responses, protease/antiprotease imbalance, and disturbed apoptosis/proliferation equilibrium are important contributors to the pathogenesis of COPD (Yao and Rahman, 2011). To date, much research has focused on the roles of senescence, autophagy, metabolism, and mitochondrial dysfunction in the development of COPD (Yue and Yao, 2016; Zhao et al., 2018). Nevertheless, further investigations are needed to determine whether potential therapeutics can be developed for this disease with these cellular processes as a basis.

ABBREVIATIONS: AMPK, AMP-activated protein kinase; APC, adenomatous polyposis coli; CBP, CREB binding protein; CK1 $\alpha$, casein kinase $1 \alpha$; COPD, chronic obstructive pulmonary disease; DAG, diacylglycerol; Dsh/Dvl, dishevelled; FZD, Frizzled; GSK3, glycogen synthase kinase 3; IL, interleukin; IP3, inositol 1,4,5-trisphosphate; JNK, c-Jun-N-terminal kinase; LEF, lymphoid enhancer-binding factor; MAPK, mitogen-activated protein kinase; MMPs, matrix metalloproteinases; PCP, planar cell polarity; ROS, reactive oxygen species; SFRP, secreted frizzled-related protein; TCF, T cell-specific transcription factor; TLR, Toll-like receptor. 


\section{Wnt Pathway and Regulation}

Canonical and Noncanonical Wnt Signal Pathway. The first Wnt gene, i.e., mouse Wnt1, was discovered in 1982 as a proto-oncogene in mammary tumors (Nusse and Varmus, 1982). Wnt signals comprise a family of signaling molecules that control a variety of developmental and physiologic processes (Willert and Nusse, 2012). Wnt signaling has been grouped into canonical ( $\beta$-catenin-dependent) and noncanonical ( $\beta$-catenin-independent) signaling pathways (Fig. 1). There are at least $19 \mathrm{Wnt}$ ligands that trigger specific and distinct Wnt pathways. In general, Wnt1, Wnt2, Wnt3A, Wnt8, and Wnt10B induce the canonical Wnt pathway, with Wnt3A the most studied ligand. In contrast, Wnt5A is the broadly studied ligand for the noncanonical Wnt signal, although Wnt4 and Wnt11 also mediate this pathway (Baarsma et al., 2013). Nevertheless, Wnt ligands are not intrinsically canonical or noncanonical, as some Wnt ligands are able to activate multiple signaling pathways.

Wnt canonical signaling is dependent on a transcription coactivator, $\beta$-catenin, which is initiated by the binding of Wnt ligands to their receptors, including a member of the Frizzled (FZD) family of serpentine receptors and the coreceptor LRP 5/6 (MacDonald and He, 2012; Baarsma and Konigshoff, 2017). This leads to the recruitment of the destruction complex to the plasma membrane and the inhibition of glycogen synthase kinase 3 (GSK3). GSK-3 is recognized as a dual-specificity kinase regulated by tyrosine and serine/threonine phosphorylation (Tejeda-Muñoz and Robles-Flores, 2015). There are two different genes that encode for GSK-3 isoforms (GSK-3 $\alpha$ and GSK-3 $\beta$ ) (Woodgett, 1990; Shaw et al., 1998). Both isoforms function redundantly in the destruction complex (Doble et al., 2007).
GSK3 inhibition results in reduced phosphorylation and degradation of $\beta$-catenin, which enhances the translocation and accumulation of $\beta$-catenin into the nucleus, where $\beta$-catenin binds to the members of the $\mathrm{T}$ cell-specific transcription factor/lymphoid enhancer-binding factor (TCF/LEF) family, leading to transcription of targeting genes (Langton et al., 2016; Muneer, 2017; Naspi et al., 2017; Skronska-Wasek et al., $2018)$. In the condition of reduced Wnt signal, $\beta$-catenin is phosphorylated and degraded via a proteasome-dependent process by the $\beta$-catenin destruction complex, which includes the scaffold proteins Axin and adenomatous polyposis coli (APC), the Ser/Thr kinases casein kinase 1, protein phosphatase 2A, and GSK3 (Taelman et al., 2010; Kaidanovich-Beilin and Woodgett, 2011; van Kappel and Maurice, 2017). Axin phosphorylation in both Wnt-off and Wnt-on states requires the tumor suppressor APC in Drosophila, suggesting a more active and multifaceted role for APC in Wnt signaling (Tacchelly-Benites et al., 2018).

The most studied noncanonical pathway is the planar cell polarity (PCP) pathway acting via c-Jun-N-terminal kinase (JNK) and the Wnt-Ca ${ }^{2+}, \mathrm{Ca}^{2+}$-dependent signal. Although activation of noncanonical Wnt signaling also requires the binding of specific Wnt ligands (e.g., Wnt-4 or Wnt-5A) to FZD receptors, it seems to be independent of LPR $5 / 6$ coreceptors. Wnt5A-dependent noncanonical Wnt signaling has been shown to inhibit Wnt3A-induced $\mathrm{Wnt} / \beta$-catenin signaling (Bryja et al., 2007), suggesting that the PCP and Wnt/ $\beta$-catenin signaling can antagonize each other.

Regulation of $\boldsymbol{\beta}$-Catenin Phosphorylation. In addition to GSK3 $\beta$, other kinases can also phosphorylate $\beta$-catenin. AKT can directly phosphorylate $\beta$-catenin at serine 552 but increases its cytoplasmic and nuclear accumulation (Fang et al., 2007). Protein kinase A activation leads to $\beta$-catenin

\section{Canonical Wnt signal}

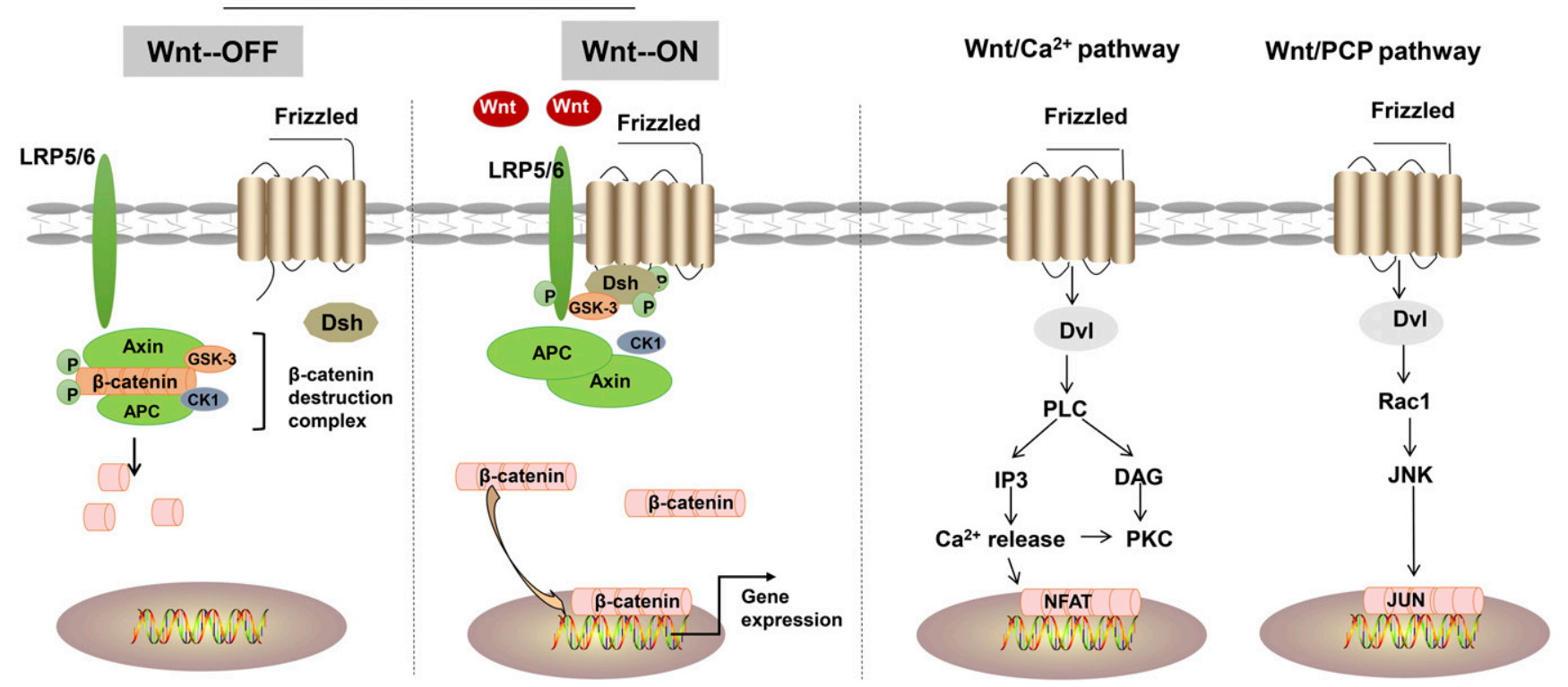

Fig. 1. Switch-on and switch-off of canonical and noncanonical Wnt signal pathway. During canonical Wnt pathway, in the absence of Wnt ligand, $\beta$-catenin is phosphorylated and degraded by a destruction complex that includes the scaffold proteins Axin and adenomatous polyposis (APC), the Ser/Thr kinases casein kinase 1 and glycogen synthase kinase 3 (GSK3). Upon Wnt activation, $\beta$-catenin translocates to the nucleus and then associates with TCF/LEF family transcription factors to activate target gene expression. The two noncanonical pathways are Wnt/calcium and PCP pathways. For Wnt/calcium pathway, Wnt stimulates calcium release, activating PLC and subsequent the transcription factor NFAT. The Wnt/PCP pathway is mediated by the activation of JNK. Dsh/Dvl: dishevelled; PLC: phospholipase C; IP3: inositol 1,4,5-triphosphate-3; DAG: diacylglycerol; NFAT: nuclear factor of activated $\mathrm{T}$ cells. 
phosphorylation at Y654 and S675, which also promotes nuclear translocation of $\beta$-catenin (Liu and Habener, 2008; Bellei et al., 2011; Law et al., 2013). There is a functional cooperation between JNK and $\beta$-catenin (Nateri et al., 2005; Lee et al., 2009). Activated JNK promotes $\beta$-catenin degradation, which is associated with increased $\beta$-catenin phosphorylation at ser33 and ser37 residues by GSK3 $\beta$ (Hu et al., 2009). This is corroborated by the finding that high levels of nuclear JNK activity in early Xenopus embryos blocked nuclear accumulation of $\beta$-catenin (Liao et al., 2006). AMP-activated protein kinase (AMPK) enhances $\beta$-catenin phosphorylation at Ser33, Ser37, and Thr41 residues and promotes the protein degradation of $\beta$-catenin by GSK3 $\beta$ in Saos- 2 cells (Takatani et al., 2011). On the contrary, AMPK phosphorylates $\beta$-catenin at Ser552, which stabilizes $\beta$-catenin and enhances $\beta$-catenin/ TCF-mediated transcription in rat mesenchymal cells (Zhao et al., 2010). These findings suggest that the $\beta$-catenin phosphorylation on its stability is residue-specific.

\section{Wnt Pathway in COPD}

Previous studies have shown that adult lung tissues express a variety of Wnt ligands (e.g., Wnt3, Wnt4, Wnt5a, Wnt7a, Wnt7b, Wnt10b, and Wnt 11), receptors (e.g., FZD3, FZD6, and FZD7), and signal components (e.g., Dvl and Dickkopf). In general, $\beta$-catenin, TCF, and Frizzled- 4 are reduced in patients with pulmonary emphysema compared with normal donors (Wang et al., 2011; Skronska-Wasek et al., 2017). In contrast, Wnt4, Wnt5a, Wnt5b, and Wnt10b are increased in patients with pulmonary emphysema (Heijink et al., 2013, 2016; Baarsma et al., 2017) (Table 1). Interestingly, secreted frizzled-related protein 1 (SFRP1), a Wnt inhibitor, is increased in lung tissues from patients with pulmonary emphysema, whereas Frizzled-8 is upregulated in patients with chronic bronchitis (Foronjy et al., 2010; Wang et al., 2011) (Table 1).

$\mathrm{Wnt} / \beta$-catenin activation by lithium chloride attenuates airspace enlargement and lung function decline in mice with pulmonary emphysema, whereas Wnt-5a overexpression in lung type II cells aggravated airspace enlargement in elastaseinduced pulmonary emphysema in mice (Kneidinger et al., 2011; Baarsma et al., 2017; Cui et al., 2018). The mechanisms are associated with the regulation of cellular processes involved in COPD as we discuss below (Fig. 2).

Oxidative Stress. Exogenous and endogenous generation of reactive oxygen species (ROS) has been shown to cause lung injury and subsequent COPD. Increased oxidative stress is also attributable to a reduced antioxidant system, including Nrf2, HO-1, superoxide dismutase (SOD), and glutathione, during the development of COPD.

It has been shown that $\mathrm{H}_{2} \mathrm{O}_{2}$ induces dephosphorylation and stabilization of $\beta$-catenin (Funato et al., 2006; Kajla et al., 2012 ), suggesting the link between oxidative stress and the Wnt $\beta$-catenin pathway. Treatment with antioxidant $N$-acetyl cysteine suppresses Wnt3a-induced dephosphorylation of $\beta$-catenin in endothelial cells (Vikram et al., 2014). This may have been the result of reduced NADPH oxidase-4-derived ROS by $N$-acetyl cysteine in response to Wnt3a treatment. Further study showed that mitochondrial ROS promoted the dissociation of Dishevelled from its complex with nucleoredoxin, which augments $\mathrm{Wnt} / \beta$-catenin signaling efficiency (Rharass et al., 2014). This was also corroborated by findings that SOD3 knockdown in mice activated Wnt $2 / \beta$-catenin signaling (Thimraj et al., 2017). Nrf2 also has the ability to inhibit Wnt/ $\beta$-catenin pathway (Manigandan et al., 2015), which is associated with the direct interaction between $\beta$-catenin $\mathrm{N}$-terminus and $\beta$-TrCP1, an antagonist of both Nrf2 and $\beta$-catenin (Long et al., 2017).

Constitutively active $\beta$-catenin expression in the endothelium increased vascular ROS and impaired endotheliumdependent vasorelaxation (Vikram et al., 2014). We have shown that Wnt3a/ $\beta$-catenin pathway activation increases Nrf2 and HO-1 levels in bronchial epithelial cells after cigarette smoke exposure, and protects against pulmonary emphysema induced by elastase in mice (Cui et al., 2018). Both Wnt and Nrf2 are reduced in retinal pigment epithelial cells when mice are exposed to chronic cigarette smoke, which is associated with GSK3 $\beta$ phosphorylation (Ebrahimi et al., 2018). In addition to $\beta$-catenin, Gsk3 $\beta$ activation via $\mathrm{p}-\mathrm{Gsk} 3 \beta$ (tyr216) is able to phosphorylate Nrf2 leading to Nrf2 degradation independent of a kelch-like ECH-associated protein 1 pathway (Rada et al., 2011). This is in agreement with findings that Wnt3a regulates an Axin1/Nrf2 complex in hepatocytes (Rada et al., 2015). All these findings suggest a bidirectional feedback loop between Wnt and Nrf2 through phosphorylated GSK3 $\beta$. The different regulation between Nrf2 and Wnt may also be owing to different cell types. Overall, targeting the Wnt/ $\beta$-catenin pathway and oxidative stress would be a promising strategy to attenuate the lung damage in COPD.

Inflammation. Abnormal inflammatory responses are observed in patients with COPD. This is the result of increased infiltration of inflammatory cells as well as release of proinflammatory mediators. Increased inflammatory response

TABLE 1

The changes of Wnt signal molecules in patients with chronic bronchitis and pulmonary emphysema

\begin{tabular}{|c|c|c|c|}
\hline Disease & Molecule & Change & Reference \\
\hline Chronic bronchitis & Frizzled-8 & Increase in bronchial epithelial cells & Spanjer et al., 2016 \\
\hline Pulmonary emphysema & SFRP1 & Increase in lung homogenates & Foronjy et al., 2010 \\
\hline \multirow[t]{8}{*}{ COPD } & Wnt4 & Increase in bronchial epithelial cells, stromal cells & Durham et al., 2013; Heijink et al., 2013 \\
\hline & Wnt5a & Increase in lung homogenates and oncosomes & van Dijk et al., 2016; Feller et al., 2018 \\
\hline & Wnt5b & Increase in bronchial epithelial cells & Heijink et al., 2016 \\
\hline & Wnt10b & Increase in lung homogenates & Kneidinger et al., 2011 \\
\hline & $\beta$-catenin & $\begin{array}{l}\text { Decrease in small-airway epithelium and lung } \\
\text { homogenates; reduction in nuclear } \beta \text {-catenin- } \\
\text { positive alveolar epithelial cells }\end{array}$ & $\begin{array}{l}\text { Kneidinger et al., 2011; Wang et al., 2011; } \\
\text { Baarsma et al., } 2017\end{array}$ \\
\hline & Frizzled-4 & Decrease in alveolar epithelial cells & Skronska-Wasek et al., 2017 \\
\hline & TCF7L1 & Decrease in lung homogenates & Wang et al., 2011 \\
\hline & SFRP2 & $\begin{array}{l}\text { Increase in small airway epithelium and lung } \\
\text { homogenates }\end{array}$ & Wang et al., 2011; Baarsma et al., 2017 \\
\hline
\end{tabular}




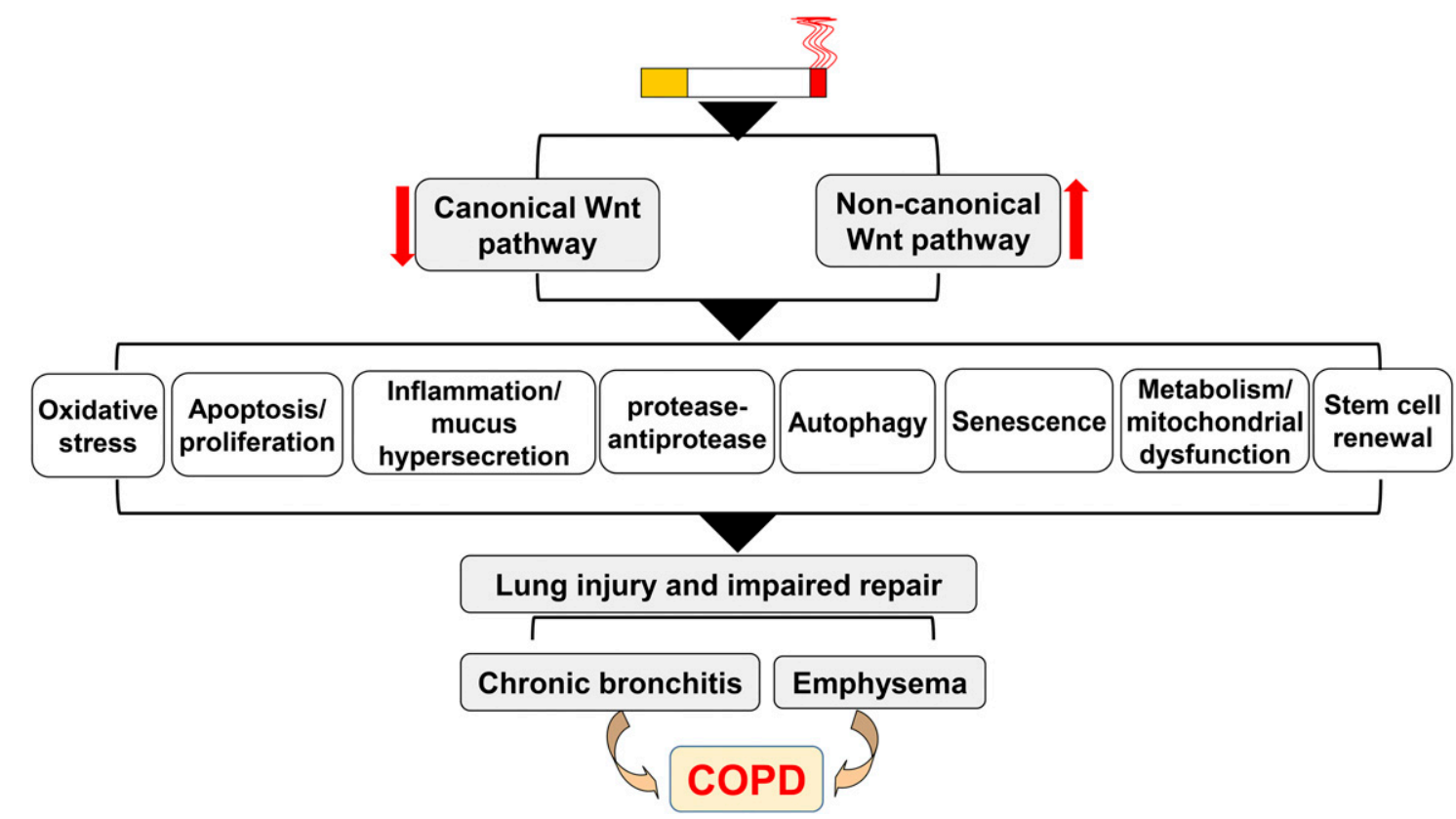

Fig. 2. Regulation of Wnt signal in the development of COPD/emphysema. Cigarette smoke exposure causes the dysregulation of canonical and noncanonical Wnt signal pathways, which results in the alteration of oxidative stress, apoptosis/proliferation, inflammation, mucus hypersecretion, protease/antiprotease imbalance, autophagy, senescence, metabolism reprograming, mitochondrial dysfunction, or stem-cell/progenitor-cell renewal. All of these cellular processes participate in the pathogenesis of chronic bronchitis or pulmonary emphysema through increased lung injury and impaired lung repair.

could lead to irreversible and progressive airflow limitation and lung function decline (Barnes, 2016). The mechanisms underlying abnormal inflammatory response are associated with activation of Toll-like receptor (TLR), mitogen-activated protein kinase (MAPK), protein kinase $\mathrm{A}$, and nuclear factor $(\mathrm{NF})-\kappa \mathrm{B}$ signal pathways.

Lipopolysaccharide-induced acute lung injury is associated with suppression of $\mathrm{Wnt} / \beta$-catenin pathway (Suo et al., 2018). Enhancing Wnt signaling is capable of attenuating TLR signaling and mediating the inflammatory response in lung alveolar epithelial cells ( $\mathrm{Li}$ et al., 2014). In macrophages, Wnt5a induces inflammatory response via FZD5, whereas Wnt3a, a ligand of FZD1, mediates anti-inflammatory effects on mycobacteria-infected macrophages via the $\mathrm{Wnt} / \beta$-catenin signaling pathway by regulating the TLR/NF- $\kappa \mathrm{B}$ pathway (Schaale et al., 2011). Treatment with recombinant Wnt5a or Wnt5b increased interleukin (IL)-6 and IL-8 release, which is higher in lung fibroblasts from COPD patients than non-COPD controls (van Dijk et al., 2016). Likewise, the noncanonical Wnt pathway activation by Wnt4 increases IL-8, IL-6, RANTES (regulated on activation normal T cell-expressed and secreted), and monocyte chemotactic protein-1 in bronchial epithelial cells (Heijink et al., 2013). This is associated with activation of p38 and JNK-MAPK pathways, leading to neutrophil infiltration and inflammation in COPD (Durham et al., 2013). This is in agreement with the finding that the proinflammatory role for the FZD-8 receptor in mucus hypersecretion by increasing MUC5AC expression during chronic bronchitis (Spanjer et al., 2016). In contrast, cigarette smoke exposure reduces the activity of Wnt/ $\beta$-catenin signaling in both bronchial epithelial cells and mice. Treatment with $\beta$-catenin activator SB216763 significantly reduces cigarette smoke extract-induced secretion of the inflammatory cytokines tumor necrosis factor $\alpha$ and IL- $1 \beta$ in bronchial epithelial cells by modulating peroxisome proliferator-activated receptor $\delta$ and the p38 MAPK pathway (Guo et al., 2016). Further study is required to determine how canonical and noncanonical Wnt signal pathways differentially modulate MAPK-dependent inflammatory responses and whether this is cell-specific.

Matrix Metalloproteinases. Imbalance of matrix metalloproteinases (MMP)/tissue inhibitor of metalloproteinases toward increased MMPs is thought to contribute to the destruction of alveoli, resulting in emphysema (Stockley et al., 2013). Findings from human disease and experimental models suggest that MMP-7, MMP-9, MMP-10, MMP-12, and MMP-28 participate in the development of COPD (Skjot-Arkil et al., 2012; Kaur et al., 2016). Both MMP-2 and MMP-9 promoters contain LEF/TCF binding sites, and Wnt activation through FZD receptor induces MMP-2 and MMP-9 gene expression in T cells (Wu et al., 2007). SFRPs can bind soluble Wnt and inhibit Wnt's interaction with FZD receptors, which antagonizes their action. SFRP1 and SFRP2 are upregulated in lung tissues of patients with pulmonary emphysema, which is associated with increased MMP-1 and MMP-9 levels (Foronjy et al., 2010; Wang et al., 2011). Although SFRP2 is specifically upregulated in the ciliated epithelial cells from healthy smokers and smokers with COPD (Wang et al., 2011), Heijink et al. (2013) were not able to detect SFRP2 expression in the epithelial cell lines. This difference could be owing to different factors present in the epithelial microenvironment (Heijink et al., 2013). Wnt5B increases levels of MMP-2 and MMP-9 in human bronchial epithelium (Heijink et al., 2016). However, exogenously added Wnt4 does not affect the genes of MMP2 and MMP9 in human bronchial epithelium after cigarette smoke exposure (Heijink et al., 2013). These findings suggest that Wnt signal regulates MMP expression in a ligand-specific manner.

Apoptosis/Proliferation. Apoptosis of lung structural cells, including epithelial cells, endothelial cells, and fibroblasts, 
contributes to the process of lung damage in COPD. This is imbalanced by reduced proliferation leading to impaired repair after lung injury. Reduced or delayed apoptosis of neutrophils is observed in COPD (Hoenderdos and Condliffe, 2013), leading to increased inflammatory responses.

FZD4 is reduced in type II cells in patients with COPD compared with nonsmokers or smokers. Overexpression of FZD4 activates the Wnt/ $\beta$-catenin pathway, and promotes type II cell proliferation and transdifferentiation into type I cells (Skronska-Wasek et al., 2017). This is corroborated by the findings that single-cell Wnt signaling niches maintain stemness of alveolar type II cells (Nabhan et al., 2018). This provides a potential therapeutic avenue for replenishment of alveolar type II cells by maintenance of canonical Wnt signal in COPD. Furthermore, treatment of MRC-5 fibroblast using basic fibroblast growth factor, a well known proliferation inducer in COPD, enhanced Wnt5a and $\beta$-catenin expressions (Ge et al., 2016). These findings suggest an important role for the Wnt canonical pathway in enhancing lung repair after injury.

Senescence. Senescence occurs in patients with COPD and in mice with emphysema (Yao et al., 2012; Ahmad et al., 2015). There are a few studies investigating the link between Wnt signal and lung aging (Kneidinger et al., 2011; Hofmann et al., 2014; Kovacs et al., 2014). For instance, a decrease in canonical Wnt signaling (e.g., Wnt3a) and an increase of noncanonical pathway (e.g., Wnt5A) are observed in aged lungs. In addition, expression of Wnt pathway-related genes are altered in lung tissues of old mice. The levels of Tle1, Tef1, and Nkd1 are decreased, whereas Frzb is increased, in lungs of older mice (36 months old) compared with young mice (5 months old) (Hofmann et al., 2014). Further studies on the role of Wnt signal in lung aging/senescence during the development of COPD may uncover novel mechanisms for this disease.

Autophagy. Autophagy, including mitophagy and ciliaphagy, has been shown to modulate the development of COPD (Cloonan et al., 2014; Ahmad et al., 2015). Autophagy negatively regulates Wnt signaling by promoting Dishevelled degradation (Gao et al., 2010), whereas inhibition of Wnt/ $\beta$-catenin signaling upregulates SQSTM1/p62 and sensitizes glioblastoma cells for proliferation and apoptosis to autophagy blockers (Nàger et al., 2018). Although SB216763, a selective small-molecule inhibitor of GSK3, protects against bleomycin-induced pulmonary fibrosis via activation of autophagy (Gurrieri et al., 2010), it remains elusive whether there is an interaction between autophagy and Wnt signaling during the development of COPD.

Mitochondrial Dysfunction. Mitochondrial dysfunction occurs in patients with COPD, and this includes abnormal mitochondrial biogenesis, fusion/fission, and mitophagy (Mizumura et al., 2014; Ahmad et al., 2015). Wnt signaling has been shown to regulate mitochondrial biogenesis and fusion/fission, which is cell- and organ-specific (An et al., 2010; Yoon et al., 2010; Godoy et al., 2014; Bernkopf and Behrens, 2018; Singh et al., 2018). For instance, activation of Wnt signal by Wnt3a results in an increase in mitochondria in human osteosarcoma cell. Wnt5a ligand modulates mitochondrial fission-fusion in rat hippocampal neurons. These findings suggest that the Wnt signal regulates mitochondrial function in a ligand-specific manner. Further investigation of the role of Wnt signal in cigarette smoke-induced mitochondrial dysfunction would provide novel insights into molecular mechanisms for COPD.

Metabolism. Lung epithelial cells exposed to cigarette smoking have shown a decrease in glycolysis but an increase in fatty acid oxidation, suggesting that metabolic dysregulation may regulate lung destruction and impaired repair in COPD (Agarwal et al., 2014; Jiang et al., 2017; Cruickshank-Quinn et al., 2018). Exposure of human lung fibroblast to cigarette smoke inhibits oxidative phosphorylation complex III (Lei et al., 2017). Proteomic analysis of livers from liver-specific APC knockout mice has shown dysregulated proteins involved in mitochondrial dysfunction and carbohydrate metabolism, suggesting that defects in Wnt signaling may contribute to a metabolic switch in fuel utilization toward glycolysis and away from fatty acid oxidation (Chafey et al., 2009). This is corroborated by the findings that Wnt signaling activates TP53-induced glycolysis (Liu et al., 2019). The mechanisms are associated with transcription factors FOXO1 and TIGAR, or direct target genes, including monocarboxylate transporter 1 and pyruvate dehydrogenase kinase 1 (Liu et al., 2011; Pate et al., 2014; Sprowl-Tanio et al., 2016). Nevertheless, it is not known whether Wnt regulates metabolic reprogramming in response to cigarette smoke exposure or in the development of COPD.

Stem Cell Renewal. Inadequate lung tissue repair after injury contributes to the development of COPD (Bagdonas et al., 2015). In the normal condition, lung tissue turnover is slow. However, after lung injury in COPD, lung stem cells or progenitor cells are activated to replace damaged lung tissue via lung regeneration (Kokturk et al., 2018). Wnt/ $\beta$-catenin signaling is involved in regulating the stem cell in the renewal of lung epithelium (Wang et al., 2009; Sun et al., 2014), suggesting that enhancing canonical Wnt signal would promote lung repair in COPD. Interestingly, knockout $\beta$-catenin in bronchiolar epithelium did not affect maintenance and repair following naphthalene-induced airway injury, indicating that $\beta$-catenin is not necessary for maintenance or repair of bronchiolar epithelium (Zemke et al., 2009). This is corroborated by the findings that low-dose Wnt treatment enhanced stem-cell proliferation, whereas high-dose treatment inhibited the proliferation of stem cells (De Boer et al., 2004). This could be attributable to the temporal and spatial effects of Wnt signaling for regenerating epithelium or endothelium after injury. Further studies are required to explore whether and how Wnt/ $\beta$-catenin signaling modulates stem-cell or progenitor-cell renewal for repairing lung tissues in COPD.

Differentiation of the alveolar type I cell lineage is an important step for the formation of distal lung saccules during the embryonic stage. Systemic activation of Wnt signaling at specific stages of lung development can partially rescue the type I cell differentiation and lung alveolarization (Wang et al., 2016). However, inhibiting Wnt/ $\beta$-catenin pathway by ICG-001 compound attenuates hyperoxia-induced simplification of alveolarization in neonatal rats (Alapati et al., 2014), whereas inhibition of Wnt receptor LRP5/6 by Mesd does not improve alveolarization during hyperoxia (Alapati et al., 2013). Accumulating evidence suggests that neonatal lung injury, such as bronchopulmonary dysplasia, can evolve into COPD. Hence, it is possible that COPD develops as a result of neonatal lung injury leading to aberrant Wnt signaling and thus lung repair capacity. This requires long-term follow-up studies in infants with bronchopulmonary dysplasia. 
TABLE 2

Compounds targeting Wnt signal pathway

\begin{tabular}{|c|c|c|c|}
\hline Target & Compound & Function & Reference \\
\hline Wnt & OMP-54F28 (FZD8-Fc fusion) & A decoy receptor of Wnt & Jimeno et al., 2017 \\
\hline Frizzled & OMP-18R5 & Binds to FZD7 and inhibits Wnt & Gurney et al., 2012 \\
\hline $\mathrm{CK} 1 \alpha$ & Pyrvinium & Activates $\mathrm{CK} 1 \alpha$ but inhibits Wnt & Thorne et al., 2010 \\
\hline$\beta$-catenin/TCF & $\begin{array}{l}\text { PKF115-584; CGP049090; iCRT3; iCRT5; } \\
\text { iCRT14; 2,4 diamino-quinazoline series; } \\
\text { PNU-74654; BC21 }\end{array}$ & $\begin{array}{l}\text { Disrupts } \beta \text {-catenin/TCF complex } \\
\text { and inhibits Wnt }\end{array}$ & $\begin{array}{l}\text { Sukhdeo et al., 2007; } \\
\text { Minke et al., 2009; } \\
\text { Gonsalves et al., } 2011\end{array}$ \\
\hline DVL & NSC 668036; FJ9; 3289-8625 & $\begin{array}{l}\text { Binds to the Dvl PDZ domain, } \\
\text { and inhibits Wnt }\end{array}$ & $\begin{array}{l}\text { Shan et al., 2005; } \\
\text { Grandy et al., } 2009\end{array}$ \\
\hline Tankyrase 1 and 2 & IWR-1; XAV939; K-756 & Inhibits tankyrase and Wnt & $\begin{array}{l}\text { Lu et al., 2009; } \\
\quad \text { Okada-Iwasaki et al., } 2016\end{array}$ \\
\hline Porcupine & IWP2; LGK974 & Inhibits porcupine, and Wnt & Liu et al., 2013 \\
\hline $\mathrm{CBP}$ & ICG-001; PRI-724 & $\begin{array}{l}\text { Inhibits } \mathrm{CBP} / \beta \text {-catenin complex, } \\
\text { and Wnt }\end{array}$ & Kimura et al., 2017 \\
\hline GSK3 & Lithium; TDZD8; SB216763; CHIR 99021 & Inhibits GSK3 but activates Wnt & $\begin{array}{l}\text { Hedgepeth et al., 1997; } \\
\text { Eldar-Finkelman and } \\
\text { Martinez, 2011; Uhl et al., } 2015\end{array}$ \\
\hline
\end{tabular}

CBP: CREB-binding protein; CK1 $\alpha$ : casein kinase $1 \alpha$; Dvl: dishevelled; TCF: T-cell factor/lymphoid enhancer factor.

\section{Pharmacologically Targeting Wnt Signal Pathway}

There are numerous pharmacological compounds targeting the Wnt signal pathway. Table 2 shows the compounds and their targets in Wnt signal pathway. Except for GSK3 inhibitors activating the canonical Wnt signal, most are inhibitors of the Wnt signal pathway. These compounds are either FDA-approved or in clinical trials as tumor treatments or at preclinical stages. A few groups report using GSK3 inhibitors to activate Wnt pathway to attenuate cigarette smoke-induced lung inflammation and injury (Baarsma et al., 2011; Kneidinger et al., 2011; Guo et al., 2016; Cui et al., 2018). Their findings suggest potential therapies for preventing or treating COPD using Wnt-signal modulators. The Wnt signal plays important roles in tissue homeostasis and cancer stem-cell proliferation and renewal in multiple organs, including lung (Wang et al., 2018). Therefore, the side effects should be considered during the development of therapeutic strategies to activate the Wnt pathway for COPD.

\section{Conclusion and Future Directions}

COPD is a chronic respiratory disease characterized by loss of parenchymal alveolar tissue and impaired tissue repair. Therapeutic targets are limited. Several studies have revealed that the Wnt signaling pathway is involved in lung development, homeostasis, and the lung epithelial injury and repair process in COPD. Targeting the Wnt signal would provide novel therapeutics to intervene in the development of COPD. Yet, the molecular mechanisms underpinning the pathogenesis of Wnt signaling components in COPD, including the destructive complex, remain largely unclear. Wnt signaling is temporal, and both the activation and subsequent reduction of Wnt signaling are required for normal homeostasis or repair after injury. Thus, it is important to study the dynamics of Wnt signal during the development of COPD. $\beta$-catenin is able to bind to a variety of transcription factors other than TCF/LEF, which modulate a broad spectrum of downstream biologic processes. Therefore, it is important to determine whether any of these therapeutic agents that specifically target the Wnt pathway will be beneficial for COPD/emphysema and have an acceptable safety profile.

\section{Authorship Contributions}

Participated in research design: Gao, Yao.

Wrote or contributed to the writing of the manuscript: $\mathrm{Qu}$, Yue, Gao, Yao.

\section{References}

Agarwal AR, Yin F, and Cadenas E (2014) Short-term cigarette smoke exposure leads to metabolic alterations in lung alveolar cells. Am J Respir Cell Mol Biol 51:284-293.

Ahmad T, Sundar IK, Lerner CA, Gerloff J, Tormos AM, Yao H, and Rahman I (2015) Impaired mitophagy leads to cigarette smoke stress-induced cellular senescence: implications for chronic obstructive pulmonary disease. FASEB J 29: $2912-2929$.

Alapati D, Rong M, Chen S, Hehre D, Hummler SC, and Wu S (2014) Inhibition of $\beta$-catenin signaling improves alveolarization and reduces pulmonary hypertension in experimental bronchopulmonary dysplasia. Am J Respir Cell Mol Biol 51:104-113.

Alapati D, Rong M, Chen S, Lin C, Li Y, and Wu S (2013) Inhibition of LRP5/6mediated Wnt/ $\beta$-catenin signaling by Mesd attenuates hyperoxia-induced pulmonary hypertension in neonatal rats. Pediatr Res 73:719-725.

An JH, Yang JY, Ahn BY, Cho SW, Jung JY, Cho HY, Cho YM, Kim SW, Park KS, Kim SY, et al. (2010) Enhanced mitochondrial biogenesis contributes to Wnt induced osteoblastic differentiation of C3H10T1/2 cells. Bone 47:140-150.

Baarsma HA and Königshoff M (2017) 'WNT-er is coming': WNT signalling in chronic lung diseases. Thorax 72:746-759.

Baarsma HA, Königshoff M, and Gosens R (2013) The WNT signaling pathway from ligand secretion to gene transcription: molecular mechanisms and pharmacological targets. Pharmacol Ther 138:66-83.

Baarsma HA, Meurs H, Halayko AJ, Menzen MH, Schmidt M, Kerstjens HA, and Gosens R (2011) Glycogen synthase kinase-3 regulates cigarette smoke extract- and IL-1 $\beta$-induced cytokine secretion by airway smooth muscle. Am $J$ Physiol Lung Cell Mol Physiol 300:L910-L919.

Baarsma HA, Skronska-Wasek W, Mutze K, Ciolek F, Wagner DE, John-Schuster G, Heinzelmann K, Günther A, Bracke KR, Dagouassat M, et al. (2017) Noncanonical WNT-5A signaling impairs endogenous lung repair in COPD. J Exp Med 214: 143-163.

Bagdonas E, Raudoniute J, Bruzauskaite I, and Aldonyte R (2015) Novel aspects of pathogenesis and regeneration mechanisms in COPD. Int $J$ Chron Obstruct Pulmon Dis 10:995-1013.

Barnes PJ (2016) Inflammatory mechanisms in patients with chronic obstructive pulmonary disease. J Allergy Clin Immunol 138:16-27.

Bellei B, Pitisci A, Catricalà C, Larue L, and Picardo M (2011) Wnt/ $\beta$-catenin signaling is stimulated by $\alpha$-melanocyte-stimulating hormone in melanoma and melanocyte cells: implication in cell differentiation. Pigment Cell Melanoma Res 24:309-325.

Bernkopf DB and Behrens J (2018) Feedback regulation of mitochondrial homeostasis via Wnt/ $\beta$-catenin signaling. Mol Cell Oncol 5:e1458015.

Bryja V, Schulte G, Rawal N, Grahn A, and Arenas E (2007) Wnt-5a induces Dishevelled phosphorylation and dopaminergic differentiation via a PP2Adependent mechanism. J Cell Sci 120:586-595.

Cabrera López C, Casanova Macario C, Marín Trigo JM, de-Torres JP, Sicilia Torres R, González JM, Divo M, Pinto Plata V, Zulueta JJ, et al. (2018) Comparison of the 2017 and 2015 global initiative for chronic obstructive lung disease reports. Impact on grouping and outcomes. Am J Respir Crit Care Med 197:463-469.

Chafey P, Finzi L, Boisgard R, Caüzac M, Clary G, Broussard C, Pégorier JP, Guillonneau F, Mayeux P, Camoin L, et al. (2009) Proteomic analysis of beta-catenin activation in mouse liver by DIGE analysis identifies glucose metabolism as a new target of the Wnt pathway. Proteomics 9:3889-3900.

Cloonan SM, Lam HC, Ryter SW, and Choi AM (2014) "Ciliophagy": the consumption of cilia components by autophagy. Autophagy 10:532-534. 
Cruickshank-Quinn CI, Jacobson S, Hughes G, Powell RL, Petrache I, Kechris K, Bowler R, and Reisdorph N (2018) Metabolomics and transcriptomics pathway approach reveals outcome-specific perturbations in COPD. Sci Rep 8:17132.

Cui W, Zhang Z, Zhang P, Qu J, Zheng C, Mo X, Zhou W, Xu L, Yao H, and Gao J (2018) Nrf2 attenuates inflammatory response in COPD/emphysema: crosstalk with Wnt3a/ß-catenin and AMPK pathways. J Cell Mol Med 22:3514-3525.

De Boer J, Wang HJ, and Van Blitterswijk C (2004) Effects of Wnt signaling on proliferation and differentiation of human mesenchymal stem cells. Tissue Eng 10:393-401.

Doble BW, Patel S, Wood GA, Kockeritz LK, and Woodgett JR (2007) Functional redundancy of GSK-3alpha and GSK-3beta in Wnt/beta-catenin signaling shown by using an allelic series of embryonic stem cell lines. Dev Cell 12:957-971.

Durham AL, McLaren A, Hayes BP, Caramori G, Clayton CL, Barnes PJ, Chung KF, and Adcock IM (2013) Regulation of Wnt4 in chronic obstructive pulmonary disease. FASEB $J$ 27:2367-2381.

Ebrahimi KB, Cano M, Rhee J, Datta S, Wang L, and Handa JT (2018) Oxidative stress induces an interactive decline in Wnt and Nrf2 signaling in degenerating retinal pigment epithelium. Antioxid Redox Signal 29:389-407.

Eldar-Finkelman H and Martinez A (2011) GSK-3 inhibitors: preclinical and clinical focus on CNS. Front Mol Neurosci 4:32.

Fang D, Hawke D, Zheng Y, Xia Y, Meisenhelder J, Nika H, Mills GB, Kobayashi R, Hunter T, and Lu Z (2007) Phosphorylation of beta-catenin by AKT promotes betacatenin transcriptional activity. J Biol Chem 282:11221-11229.

Feller D, Kun J, Ruzsics I, Rapp J, Sarosi V, Kvell K, Helyes Z, and Pongracz JE (2018) Cigarette smoke-induced pulmonary inflammation becomes systemic by circulating extracellular vesicles containing Wnt5a and inflammatory cytokines Front Immunol 9:1724.

Foronjy R, Imai K, Shiomi T, Mercer B, Sklepkiewicz P, Thankachen J, Bodine P, and D'Armiento J (2010) The divergent roles of secreted frizzled related protein-1 (SFRP1) in lung morphogenesis and emphysema. Am J Pathol 177:598-607.

Funato Y, Michiue T, Asashima M, and Miki H (2006) The thioredoxin-related redoxregulating protein nucleoredoxin inhibits Wnt-beta-catenin signalling through dishevelled. Nat Cell Biol 8:501-508.

Gao C, Cao W, Bao L, Zuo W, Xie G, Cai T, Fu W, Zhang J, Wu W, Zhang X, et al. (2010) Autophagy negatively regulates Wnt signalling by promoting Dishevelled degradation. Nat Cell Biol 12:781-790.

Ge Z, Li B, Zhou X, Yang Y, and Zhang J (2016) Basic fibroblast growth factor activates $\beta$-catenin/RhoA signaling in pulmonary fibroblasts with chronic obstructive pulmonary disease in rats. Mol Cell Biochem 423:165-174.

Godoy JA, Arrázola MS, Ordenes D, Silva-Alvarez C, Braidy N, and Inestrosa NC (2014) Wnt-5a ligand modulates mitochondrial fission-fusion in rat hippocampal neurons. J Biol Chem 289:36179-36193.

Gonsalves FC, Klein K, Carson BB, Katz S, Ekas LA, Evans S, Nagourney R, Cardozo T, Brown AM, and DasGupta R (2011) An RNAi-based chemical genetic screen identifies three small-molecule inhibitors of the Wnt/wingless signaling pathway. Proc Natl Acad Sci USA 108:5954-5963.

Grandy D, Shan J, Zhang X, Rao S, Akunuru S, Li H, Zhang Y, Alpatov I, Zhang XA, Lang RA, et al. (2009) Discovery and characterization of a small molecule inhibitor of the PDZ domain of dishevelled. J Biol Chem 284:16256-16263.

Guo L, Wang T, Wu Y, Yuan Z, Dong J, Li X, An J, Liao Z, Zhang X, Xu D, et al. (2016) $\mathrm{WNT} / \beta$-catenin signaling regulates cigarette smoke-induced airway inflammation via the PPAR8/p38 pathway. Lab Invest 96:218-229.

Gurney A, Axelrod F, Bond CJ, Cain J, Chartier C, Donigan L, Fischer M, Chaudhari A, Ji M, Kapoun AM, et al. (2012) Wnt pathway inhibition via the targeting of Frizzled receptors results in decreased growth and tumorigenicity of human tumors. Proc Natl Acad Sci USA 109:11717-11722.

Gurrieri C, Piazza F, Gnoato M, Montini B, Biasutto L, Gattazzo C, Brunetta E, Cabrelle A, Cinetto F, Niero R, et al. (2010) 3-(2,4-dichlorophenyl)-4-(1-methyl-1Hindol-3-yl)-1H-pyrrole-2,5-dione (SB216763), a glycogen synthase kinase-3 inhibitor, displays therapeutic properties in a mouse model of pulmonary inflammation and fibrosis. J Pharmacol Exp Ther 332:785-794.

Hedgepeth CM, Conrad LJ, Zhang J, Huang HC, Lee VM, and Klein PS (1997) Activation of the Wnt signaling pathway: a molecular mechanism for lithium action. Dev Biol 185:82-91.

Heijink IH, de Bruin HG, Dennebos R, Jonker MR, Noordhoek JA, Brandsma CA van den Berge M, and Postma DS (2016) Cigarette smoke-induced epithelial expression of WNT-5B: implications for COPD. Eur Respir J 48:504-515.

Heijink IH, de Bruin HG, van den Berge M, Bennink LJ, Brandenburg SM, Gosens R, van Oosterhout AJ, and Postma DS (2013) Role of aberrant WNT signalling in the airway epithelial response to cigarette smoke in chronic obstructive pulmonary disease. Thorax 68:709-716.

Hoenderdos K and Condliffe A (2013) The neutrophil in chronic obstructive pulmonary disease. Am J Respir Cell Mol Biol 48:531-539.

Hofmann JW, McBryan T, Adams PD, and Sedivy JM (2014) The effects of aging on the expression of Wnt pathway genes in mouse tissues. Age (Dordr) 36:9618.

Hu D, Bi X, Fang W, Han A, and Yang W (2009) GSK3beta is involved in JNK2mediated beta-catenin inhibition. PLoS One 4:e6640.

Jiang Z, Knudsen NH, Wang G, Qiu W, Naing ZZC, Bai Y, Ai X, Lee CH, and Zhou X (2017) Genetic control of fatty acid $\beta$-oxidation in chronic obstructive pulmonary disease. Am J Respir Cell Mol Biol 56:738-748.

Jimeno A, Gordon M, Chugh R, Messersmith W, Mendelson D, Dupont J, Stagg R, Kapoun AM, Xu L, Uttamsingh S, et al. (2017) A first-in-human phase I study of the anticancer stem cell agent ipafricept (OMP-54F28), a decoy receptor for Wnt ligands, in patients with advanced solid tumors. Clin Cancer Res 23 : $7490-7497$.

Kaidanovich-Beilin O and Woodgett JR (2011) GSK-3: functional insights from cell biology and animal models. Front Mol Neurosci 4:40.

Kajla S, Mondol AS, Nagasawa A, Zhang Y, Kato M, Matsuno K, Yabe-Nishimura C and Kamata T (2012) A crucial role for Nox 1 in redox-dependent regulation of Wnt- $\beta$-catenin signaling. FASEB J 26:2049-2059.
Kaur N, Singla RK, and Kullar JS (2016) Martin-Gruber anastomosis- a cadaveric study in North Indian population. $J$ Clin Diagn Res 10:AC09-AC11.

Kimura K, Ikoma A, Shibakawa M, Shimoda S, Harada K, Saio M, Imamura J, Osawa Y, Kimura M, Nishikawa K, et al. (2017) Safety, tolerability, and preliminary efficacy of the anti-fibrotic small molecule PRI-724, a CBP/ $\beta$-catenin inhibitor, in patients with hepatitis $\mathrm{C}$ virus-related cirrhosis: a single-center, open-label, dose escalation phase 1 trial. EBioMedicine 23:79-87.

Kneidinger N, Yildirim AO, Callegari J, Takenaka S, Stein MM, Dumitrascu R, Bohla A, Bracke KR, Morty RE, Brusselle GG, et al. (2011) Activation of the WNT/ $\beta$-catenin pathway attenuates experimental emphysema. Am J Respir Crit Care Med 183:723-733.

Kokturk N, Yıldırım F, Gülhan PY, and Oh YM (2018) Stem cell therapy in chronic obstructive pulmonary disease. How far is it to the clinic? Am J Stem Cells 7: $56-71$.

Kovacs T, Csongei V, Feller D, Ernszt D, Smuk G, Sarosi V, Jakab L, Kvell K, Bartis $\mathrm{D}$, and Pongracz JE (2014) Alteration in the Wnt microenvironment directly regulates molecular events leading to pulmonary senescence. Aging Cell 13:838-849.

Langton PF, Kakugawa S, and Vincent JP (2016) Making, exporting, and modulating Wnts. Trends Cell Biol 26:756-765.

Law NC, Weck J, Kyriss B, Nilson JH, and Hunzicker-Dunn M (2013) Lhcgr expression in granulosa cells: roles for PKA-phosphorylated $\beta$-catenin, TCF3, and FOXO1. Mol Endocrinol 27:1295-1310.

Lee MH, Koria P, Qu J, and Andreadis ST (2009) JNK phosphorylates beta-catenin and regulates adherens junctions. FASEB $J$ 23:3874-3883.

Lei W, Lerner C, Sundar IK, and Rahman I (2017) Myofibroblast differentiation and its functional properties are inhibited by nicotine and e-cigarette via mitochondrial OXPHOS complex III. Sci Rep 7:43213.

Li Y, Shi J, Yang J, Ma Y, Cheng L, Zeng J, Hao X, Ma C, Wang Y, and Liu X (2014) A Wnt/ $\beta$-catenin negative feedback loop represses TLR-triggered inflammatory responses in alveolar epithelial cells. Mol Immunol 59:128-135.

Liao G, Tao Q, Kofron M, Chen JS, Schloemer A, Davis RJ, Hsieh JC, Wylie C, Heasman J, and Kuan CY (2006) Jun NH2-terminal kinase (JNK) prevents nuclear beta-catenin accumulation and regulates axis formation in Xenopus embryos. Proc Natl Acad Sci USA 103:16313-16318.

Liu H, Fergusson MM, Wu JJ, Rovira II, Liu J, Gavrilova O, Lu T, Bao J, Han D, Sack MN, et al. (2011) Wnt signaling regulates hepatic metabolism. Sci Signal 4:ra6.

Liu J, Pan S, Hsieh MH, Ng N, Sun F, Wang T, Kasibhatla S, Schuller AG, Li AG, Cheng D, et al. (2013) Targeting Wnt-driven cancer through the inhibition of porcupine by LGK974. Proc Natl Acad Sci USA 110:20224-20229.

Liu W, Xu X, Fan Z, Sun G, Han Y, Zhang D, Xu L, Wang M, Wang X, Zhang S, et al. (2019) Wnt signaling activates TP53-induced glycolysis and apoptosis regulator and protects against cisplatin-induced spiral ganglion neuron damage in the mouse cochlea. Antioxid Redox Signal 30:1389-1410.

Liu Z and Habener JF (2008) Glucagon-like peptide-1 activation of TCF7L2dependent Wnt signaling enhances pancreatic beta cell proliferation. J Biol Chem 283:8723-8735.

Long MJ, Lin HY, Parvez S, Zhao Y, Poganik JR, Huang P, and Aye Y (2017) $\beta$-TrCP1 is a vacillatory regulator of Wnt signaling. Cell Chem Biol 24:944-957.e7.

Lu J, Ma Z, Hsieh JC, Fan CW, Chen B, Longgood JC, Williams NS, Amatruda JF, Lum L, and Chen C (2009) Structure-activity relationship studies of smallmolecule inhibitors of Wnt response. Bioorg Med Chem Lett 19:3825-3827.

MacDonald BT and He X (2012) Frizzled and LRP5/6 receptors for Wnt/ $\beta$-catenin signaling. Cold Spring Harb Perspect Biol 4.

Manigandan K, Manimaran D, Jayaraj RL, Elangovan N, Dhivya V, and Kaphle A (2015) Taxifolin curbs NF-кB-mediated Wnt/ $\beta$-catenin signaling via up-regulating Nrf2 pathway in experimental colon carcinogenesis. Biochimie 119:103-112.

Minke KS, Staib P, Puetter A, Gehrke I, Gandhirajan RK, Schlösser A, Schmitt EK, Hallek M, and Kreuzer KA (2009) Small molecule inhibitors of WNT signaling effectively induce apoptosis in acute myeloid leukemia cells. Eur J Haematol 82:165-175.

Mizumura K, Cloonan SM, Nakahira K, Bhashyam AR, Cervo M, Kitada T, Glass K, Owen CA, Mahmood A, Washko GR, et al. (2014) Mitophagy-dependent necroptosis contributes to the pathogenesis of COPD. J Clin Invest 124:3987-4003.

Muneer A (2017) Wnt and GSK3 signaling pathways in bipolar disorder: clinical and therapeutic implications. Clin Psychopharmacol Neurosci 15:100-114.

Nabhan AN, Brownfield DG, Harbury PB, Krasnow MA, and Desai TJ (2018) Singlecell Wnt signaling niches maintain stemness of alveolar type 2 cells. Science 359:1118-1123.

Nàger M, Sallán MC, Visa A, Pushparaj C, Santacana M, Macià A, Yeramian A, Cantí C, and Herreros J (2018) Inhibition of WNT-CTNNB1 signaling upregulates SQSTM1 and sensitizes glioblastoma cells to autophagy blockers. Autophagy 14:619-636.

Naspi A, Zingariello M, Sancillo L, Panasiti V, Polinari D, Martella M, Rosa Alba R, and Londei P (2017) IGFBP-3 inhibits Wnt signaling in metastatic melanoma cells. Mol Carcinog 56:681-693.

Nateri AS, Spencer-Dene B, and Behrens A (2005) Interaction of phosphorylated c-Jun with TCF4 regulates intestinal cancer development. Nature 437:281-285.

Nusse R and Varmus HE (1982) Many tumors induced by the mouse mammary tumor virus contain a provirus integrated in the same region of the host genome. Cell 31:99-109.

Okada-Iwasaki R, Takahashi Y, Watanabe Y, Ishida H, Saito J, Nakai R, and Asai A (2016) The discovery and characterization of K-756, a novel Wnt/ß-catenin pathway inhibitor targeting tankyrase. Mol Cancer Ther 15:1525-1534.

Pate KT, Stringari C, Sprowl-Tanio S, Wang K, TeSlaa T, Hoverter NP, McQuade MM, Garner C, Digman MA, Teitell MA, et al. (2014) Wnt signaling directs a metabolic program of glycolysis and angiogenesis in colon cancer. EMBO J 33:1454-1473.

Rada P, Rojo AI, Chowdhry S, McMahon M, Hayes JD, and Cuadrado A (2011) SCF/beta-TrCP promotes glycogen synthase kinase 3-dependent degradation of the 
Nrf2 transcription factor in a Keap1-independent manner. Mol Cell Biol 31:1121-1133.

Rada P, Rojo AI, Offergeld A, Feng GJ, Velasco-Martín JP, González-Sancho JM Valverde AM, Dale T, Regadera J, and Cuadrado A (2015) WNT-3A regulates an Axin1/NRF2 complex that regulates antioxidant metabolism in hepatocytes. Antioxid Redox Signal 22:555-571.

Rharass T, Lemcke H, Lantow M, Kuznetsov SA, Weiss DG, and Panáková D (2014) $\mathrm{Ca} 2+-$ mediated mitochondrial reactive oxygen species metabolism augments Wnt/ $\beta$-catenin pathway activation to facilitate cell differentiation. J Biol Chem 289:27937-27951.

Schaale K, Neumann J, Schneider D, Ehlers S, and Reiling N (2011) Wnt signaling in macrophages: augmenting and inhibiting mycobacteria-induced inflammatory responses. Eur J Cell Biol 90:553-559.

Shan J, Shi DL, Wang J, and Zheng J (2005) Identification of a specific inhibitor of the dishevelled PDZ domain. Biochemistry 44:15495-15503.

Shaw PC, Davies AF, Lau KF, Garcia-Barcelo M, Waye MM, Lovestone S, Miller CC, and Anderton BH (1998) Isolation and chromosomal mapping of human glycogen synthase kinase-3 alpha and -3 beta encoding genes. Genome 41:720-727.

Singh S, Mishra A, Mohanbhai SJ, Tiwari V, Chaturvedi RK, Khurana S, and Shukla $\mathrm{S}$ (2018) Axin-2 knockdown promote mitochondrial biogenesis and dopaminergic neurogenesis by regulating Wnt/ $\beta$-catenin signaling in rat model of Parkinson's disease. Free Radic Biol Med 129:73-87.

Skjøt-Arkil H, Clausen RE, Nguyen QH, Wang Y, Zheng Q, Martinez FJ, Hogaboam CM, Han M, Klickstein LB, Larsen MR, et al. (2012) Measurement of MMP-9 and -12 degraded elastin (ELM) provides unique information on lung tissue degradation. BMC Pulm Med 12:34.

Skronska-Wasek W, Gosens R, Königshoff M, and Baarsma HA (2018) WNT receptor signalling in lung physiology and pathology. Pharmacol Ther 187:150-166.

Skronska-Wasek W, Mutze K, Baarsma HA, Bracke KR, Alsafadi HN, Lehmann M, Costa R, Stornaiuolo M, Novellino E, Brusselle GG, et al. (2017) Reduced frizzled receptor 4 expression prevents WNT/ $\beta$-catenin-driven alveolar lung repair in chronic obstructive pulmonary disease. Am J Respir Crit Care Med 196:172-185.

Spanjer AI, Menzen MH, Dijkstra AE, van den Berge M, Boezen HM, Nickle DC, Sin DD, Bossé Y, Brandsma CA, Timens W, et al. (2016) A pro-inflammatory role for the frizzled-8 receptor in chronic bronchitis. Thorax 71:312-322.

Sprowl-Tanio S, Habowski AN, Pate KT, McQuade MM, Wang K, Edwards RA, Grun F, Lyou Y, and Waterman ML (2016) Lactate/pyruvate transporter MCT-1 is a direct Wnt target that confers sensitivity to 3-bromopyruvate in colon cancer. Cancer Metab 4:20.

Stockley JA, Walton GM, Lord JM, and Sapey E (2013) Aberrant neutrophil functions in stable chronic obstructive pulmonary disease: the neutrophil as an immunotherapeutic target. Int Immunopharmacol 17:1211-1217.

Sukhdeo K, Mani M, Zhang Y, Dutta J, Yasui H, Rooney MD, Carrasco DE, Zheng M, He H, Tai YT, et al. (2007) Targeting the beta-catenin/TCF transcriptional complex in the treatment of multiple myeloma. Proc Natl Acad Sci USA 104:7516-7521.

Sun Z, Gong X, Zhu H, Wang C, Xu X, Cui D, Qian W, and Han X (2014) Inhibition of Wnt/B-catenin signaling promotes engraftment of mesenchymal stem cells to repair lung injury. J Cell Physiol 229:213-224.

Suo T, Chen GZ, Huang Y, Zhao KC, Wang T, and Hu K (2018) miRNA-1246 suppresses acute lung injury-induced inflammation and apoptosis via the NF-kB and Wnt/ß-catenin signal pathways. Biomed Pharmacother 108:783-791.

Tacchelly-Benites O, Wang Z, Yang E, Benchabane H, Tian A, Randall MP, and Ahmed Y (2018) Axin phosphorylation in both Wnt-off and Wnt-on states requires the tumor suppressor APC. PLoS Genet 14:e1007178.

Taelman VF, Dobrowolski R, Plouhinec JL, Fuentealba LC, Vorwald PP, Gumper I, Sabatini DD, and De Robertis EM (2010) Wnt signaling requires sequestration of glycogen synthase kinase 3 inside multivesicular endosomes. Cell 143:1136-1148.

Takatani T, Minagawa M, Takatani R, Kinoshita K, and Kohno Y (2011) AMPactivated protein kinase attenuates Wnt/ $\beta$-catenin signaling in human osteoblastic Saos-2 cells. Mol Cell Endocrinol 339:114-119.

Tejeda-Muñoz N and Robles-Flores M (2015) Glycogen synthase kinase 3 in Wnt signaling pathway and cancer. IUBMB Life 67:914-922.

Thimraj TA, Birru RL, Mitra A, Schulz H, Leikauf GD, and Ganguly K (2017) Homeobox, Wnt, and fibroblast growth factor signaling is augmented during alveogenesis in mice lacking superoxide dismutase 3, extracellular. Hai 195: $263-270$.
Thorne CA, Hanson AJ, Schneider J, Tahinci E, Orton D, Cselenyi CS, Jernigan KK, Meyers KC, Hang BI, Waterson AG, et al. (2010) Small-molecule inhibition of Wnt signaling through activation of casein kinase 1 $\alpha$. Nat Chem Biol 6:829-836.

Uhl FE, Vierkotten S, Wagner DE, Burgstaller G, Costa R, Koch I, Lindner M, Meiners S, Eickelberg O, and Königshoff M (2015) Preclinical validation and imaging of Wntinduced repair in human 3D lung tissue cultures. Eur Respir J 46:1150-1166.

van Dijk EM, Menzen MH, Spanjer AI, Middag LD, Brandsma CA and Gosens $\mathrm{R}$ (2016) Noncanonical WNT-5B signaling induces inflammatory responses in human lung fibroblasts. Am J Physiol Lung Cell Mol Physiol 310:L1166-L1176.

van Kappel EC and Maurice MM (2017) Molecular regulation and pharmacological targeting of the $\beta$-catenin destruction complex. $\mathrm{Br} J$ Pharmacol 174: 4575-4588.

Vikram A, Kim YR, Kumar S, Naqvi A, Hoffman TA, Kumar A, Miller FJ Jr, Kim CS, and Irani K (2014) Canonical Wnt signaling induces vascular endothelial dysfunction via p66Shc-regulated reactive oxygen species. Arterioscler Thromb Vasc Biol 34:2301-2309.

Wang J, Chen J, Jiang Y, Shi Y, Zhu J, Xie C, Geng S, Wu J, Zhang Q, Wang X, et al. (2018) Wnt/ $\beta$-catenin modulates chronic tobacco smoke exposure-induced acquisition of pulmonary cancer stem cell properties and diallyl trisulfide intervention. Toxicol Lett 291:70-76.

Wang R, Ahmed J, Wang G, Hassan I, Strulovici-Barel Y, Hackett NR, and Crystal RG (2011) Down-regulation of the canonical Wnt $\beta$-catenin pathway in the airway epithelium of healthy smokers and smokers with COPD. PLoS One 6:e14793.

Wang X, Wang Y, Snitow ME, Stewart KM, Li S, Lu M, and Morrisey EE (2016) Expression of histone deacetylase 3 instructs alveolar type I cell differentiation by regulating a Wnt signaling niche in the lung. Dev Biol 414:161-169.

Wang Y, Sun Z, Qiu X, Li Y, Qin J, and Han X (2009) Roles of Wnt/beta-catenin signaling in epithelial differentiation of mesenchymal stem cells. Biochem Biophys Res Commun 390:1309-1314.

Willert K and Nusse R (2012) Wnt proteins. Cold Spring Harb Perspect Biol 4:a007864.

Woodgett JR (1990) Molecular cloning and expression of glycogen synthase kinase3/factor A. EMBO J 9:2431-2438.

Wu B, Crampton SP, and Hughes CC (2007) Wnt signaling induces matrix metalloproteinase expression and regulates $\mathrm{T}$ cell transmigration. Immunity 26:227-239.

Yao H, Chung S, Hwang JW, Rajendrasozhan S, Sundar IK, Dean DA, McBurney MW, Guarente L, Gu W, Rönty M, et al. (2012) SIRT1 protects against emphysema via FOXO3-mediated reduction of premature senescence in mice. $J$ Clin Invest 122:2032-2045.

Yao H and Rahman I (2011) Current concepts on oxidative/carbonyl stress, inflammation and epigenetics in pathogenesis of chronic obstructive pulmonary disease. Toxicol Appl Pharmacol 254:72-85.

Yoon JC, Ng A, Kim BH, Bianco A, Xavier RJ, and Elledge SJ (2010) Wnt signaling regulates mitochondrial physiology and insulin sensitivity. Genes Dev 24:1507-1518.

Yue L and Yao H (2016) Mitochondrial dysfunction in inflammatory responses and cellular senescence: pathogenesis and pharmacological targets for chronic lung diseases. Br J Pharmacol 173:2305-2318

Zemke AC, Teisanu RM, Giangreco A, Drake JA, Brockway BL, Reynolds SD, and Stripp BR (2009) beta-Catenin is not necessary for maintenance or repair of the bronchiolar epithelium. Am J Respir Cell Mol Biol 41:535-543.

Zhao H, Dennery PA, and Yao H (2018) Metabolic reprogramming in the pathogenesis of chronic lung diseases, including BPD, COPD, and pulmonary fibrosis. Am J Physiol Lung Cell Mol Physiol 314:L544-L554.

Zhao J, Yue W, Zhu MJ, Sreejayan N, and Du M (2010) AMP-activated protein kinase (AMPK) cross-talks with canonical Wnt signaling via phosphorylation of betacatenin at Ser 552. Biochem Biophys Res Commun 395:146-151.

Address correspondence to: Dr. Jian Gao, The First Affiliated Hospital of Anhui Medical University, Jixi Road 218, Hefei, Anhui 230022, China. E-mail: gaojianayfy@163.com; or Dr. Hongwei Yao, Department of Molecular Biology, Cell Biology and Biochemistry, Brown University Alpert Medical School, 185 Meeting Street, Providence, RI 02912. E-mail: Hongwei_Yao@brown.edu 